\title{
Investigation of the Boriding Process of the Ti-Al Intermetallic Alloy GE48-2-2 Taking into Account the Probability of the Influence of the Substrate Modification
}

\author{
Dimitrios I. Zagkliveris, Georgios K. Triantafyllidis \\ Department of Chemical Engineering, Aristotle University of Thessaloniki, Thessaloniki, Greece \\ Email: zagklive@cheng.auth.gr,gktrian@auth.gr
}

How to cite this paper: Zagkliveris, D.I. and Triantafyllidis, G.K. (2018) Investigation of the Boriding Process of the Ti-Al Intermetallic Alloy GE48-2-2 Taking into Account the Probability of the Influence of the Substrate Modification. Materials Sciences and Applications, 9, 873-882.

https://doi.org/10.4236/msa.2018.911063

Received: September 14, 2018

Accepted: October 23, 2018

Published: October 26, 2018

Copyright $\odot 2018$ by authors and Scientific Research Publishing Inc. This work is licensed under the Creative Commons Attribution International License (CC BY 4.0).

http://creativecommons.org/licenses/by/4.0/

\begin{abstract}
Boriding of the Ti-Al intermetallic GE48-2-2 at $1273 \mathrm{~K}$ for 10 hours was performed. In order to ensure that no any serious alteration occurred in the substrate, it was previously examined with X-Ray Diffractometry (XRD), after it has undergone an annealing process at the temperature of boronizing. Subsequently, we examined the coating with XRD and Scanning Electron Microscopy, in order to characterize its structure and morphology. A dense $\mathrm{TiB}_{2}$ layer, 10 - $15 \mu \mathrm{m}$ thick, was formed, but also $\mathrm{Cr}_{2} \mathrm{~B}_{3}$ and $\mathrm{NbN}, \mathrm{BN}$ and some $\mathrm{Ti}$-Al phases were detected. Efforts were undertaken to focus on influence of the substrate modification, towards the quality of the coating.
\end{abstract}

\section{Keywords}

Titanium Aluminide, Boriding, Titanium Boride, Substrate Modification, Phase Analysis, X-Ray Diffraction

\section{Introduction}

The Ti-Al intermetallics are light, high-temperature oxidation resistant materials and can find application in automotive, aerospace and power industry [1]. They could replace Ni superalloys in these applications [1], as they have almost two times lower density. They are also more sufficient than pure titanium due to their higher elastic modulus and strength and better oxidation resistance at high temperatures [1]. These properties result from the dominant presence of the $\gamma$-TiAl phase. In such a way Ti-Al intermetallic is a promising group of light and high-temperature oxidation and creep resistant materials [1]. Moreover in order 
to improve these interesting properties, some alloying elements could be added. For instance, $\mathrm{Nb}$ and $\mathrm{Ta}$ addition improves the oxidation and creep resistance at $1000 \mathrm{~K}$ [2] [3]. In particular, $\mathrm{Nb}$ hinders dislocation slip resulting to the increase of creep resistance at high temperatures and, additionally, contributes to oxidation resistance by supporting the formation of an $\mathrm{Al}_{2} \mathrm{O}_{3}$ film, a kind of passivation [4].

In spite of their interesting properties, these materials show insufficient hardness values, so that makes them to be inappropriate for applications towards wear resistance requirements [2]. In order to encounter this weakness, a lot of surface treatments have been developed, included diffusion heat treatments such as aluminizing [5], nitriding [6], siliconizing [7] and other techniques as well. Boriding (or boronizing) method is not applied extensively on Ti-Al intermetallics, in spite of this method is widely used in similar applications, even on titanium alloys [8] [9]. By this technique, a layer of metal borides is formed on the surface of the metal with diffusion of boron atoms through the metal lattice.

The most commonly used technique is conventional powder-pack boriding, which is characterized by its simplicity and cost-effectiveness [10]. It is often performed using a powder that contains the boron agent, an activator and a filler material at a high temperature, which causes the boron to be released from the agent by the activator. After the boron is released, it diffuses interstitially into the titanium aluminide lattice.

It is important to emphasize that there is not much data related to the boriding process especially on $\mathrm{Ti}-\mathrm{Al}$ intermetallics. On this topic a rather new and sufficiently comprehensive work it is found at reference [11]. In our work, we investigated the role of the substrate modification, caused by the heat treatment, and the effect of the residual atmospheric gases in the structure and composition of the coating. Such an investigation on a borided Ti-Al intermetallic alloy, focused on the influence of the substrate, is totally absent from literature.

\section{Material and Methods}

\subsection{Preliminary Work}

The alloy that used is the GE48-2-2 Ti-Al intermetallic with the chemical composition, as provided by the manufacturer ( GfE-Gesellschaft für Elektrometallurgie $m b H)$, presented in Table 1 .

Ti-Al GE48-2-2 ingots are manufactured by double or triple VAR melting with consumable electrodes. Consumable electrodes are made up of compacted Ti sponge, Aluminum and master alloys [12].

The material has been cut into cubic samples with $1 \mathrm{~cm}$ long edge. Before boriding process, the samples were ground on $\mathrm{SiC}$ papers and then washed and dried.

At the same time, the boriding powder was prepared. Its composition and grain size information is presented in Table 2. 
Table 1. Chemical composition of the intermetallic GE48-2-2.

\begin{tabular}{ccccccc}
\hline Element & $\mathrm{Ti}$ & $\mathrm{Al}$ & $\mathrm{Nb}$ & $\mathrm{Cr}$ & $\mathrm{Fe}$ & $\mathrm{Si}$ \\
\hline wt. \% (precise) & 59.7 & 33.2 & 4.4 & 2.5 & 0.03 & 0.004 \\
at. \% (nominal) & 48 & 48 & 2 & 2 & - & - \\
\hline
\end{tabular}

Table 2. Chemical composition of the intermetallic GE48-2-2.

\begin{tabular}{cccc}
\hline Substance & Weight ratio in the powder & Grain size $(\mu \mathrm{m})$ & Purpose of use \\
\hline $\mathrm{SiC}$ & 0.8 & 35 (average) & Filling material \\
$\mathrm{B}_{4} \mathrm{C}$ & 0.1 & $22-59$ & Boron source \\
$\mathrm{KBF}_{4}$ & 0.1 & [Undefined] & Activator \\
\hline
\end{tabular}

\subsection{The Boriding Process}

The sample was placed in a high-temperature resistant porcelain crucible full of the boriding powder. The crucible was sealed in a larger container with a continuous Argon flow, in order to create an inert atmosphere to avoid oxidation.

The sample with the above described boriding experimental plant was put into a CARBOLITE ${ }^{\text {ma }}$ CWF 1300 furnace. The boriding process was carried out for 10 hours at $1273 \mathrm{~K}$. After the end of the cycle, the specimens were left to cool down slowly in the furnace. The boriding conditions selected after a literature research in boronizing studies on $\mathrm{Ti}-\mathrm{Al}$ and $\mathrm{Ti}$ alloys [10] [11] [13] [14].

\subsection{XRD Analysis}

XRD analysis method was selected to characterize the crystal structure of the substrate, with and without the thermal cycle. Also, Ti boride formation was verified via this method.

The measurements were carried out with a Bruker D8 ADVANCE device. A $\mathrm{Cu}$ Ka tube with $1.54060 \AA$ A wave length was used. The measurements were taken within a $2 \theta$ angle range of $25-85$ degrees with a step of 0.02 degrees and $1.0 \mathrm{sec}$ time exposure for every measured angle.

We also carried out extra measurements within a sub-range of $2 \theta$ angle with the same step, but $5.000 \mathrm{sec}$ time exposure. Thereby, we achieved to produce a high quality pattern at the sub-range that includes the majority of the information of the whole pattern.

The evaluation of the patterns was carried out via Bruker's DIFFRAC.EVA V.4.2.0.31 suite, drawing data from Crystallographic Open Database (COD-2016).

\subsection{SEM Analysis}

As a complementary characterization method, Scanning Electron Microscopy was used for taking high resolution images of the coating layer and for having a semi-quantitative chemical analysis for the area of the coating and below it. 


\section{Results and Discussion}

Figure 1 shows XRD pattern of the substrate material GE48-2-2 Titanium Aluminide before any treatment.

In order to separate overlapping peaks, we proceeded to an additional measurement with five times larger exposure time $(5.0 \mathrm{sec})$ within a $2 \theta$ range of $36-$ 48 degrees, which is shown in Figure 2. It is clear that, in the pre-treatment substrate, the dominant phase is the $\gamma$-Titanium Aluminide $(\gamma$-TiAl $)$, but there is a presence of another equilibrium Ti-Al phase consisted of $\alpha_{2}-\mathrm{Ti}_{3} \mathrm{Al}$. These preliminary measurements were carried out for two reasons: first, to detect the initial phases of the raw material and, second, to have a reference to evaluate the possible modification of the substrate after the boronizing treatment.

In Figure 3 the XRD spectrum of the substrate metal after 10 hours non-boriding annealing treatment at $1073 \mathrm{~K}, 1173 \mathrm{~K}$ and $1273 \mathrm{~K}$ is presented. The measurements, which were carried out at room temperature, showed that the substrate was modified and transformed into a pure $\gamma$-TiAl material, ensuring that during boriding the substrate consists of just one single phase.

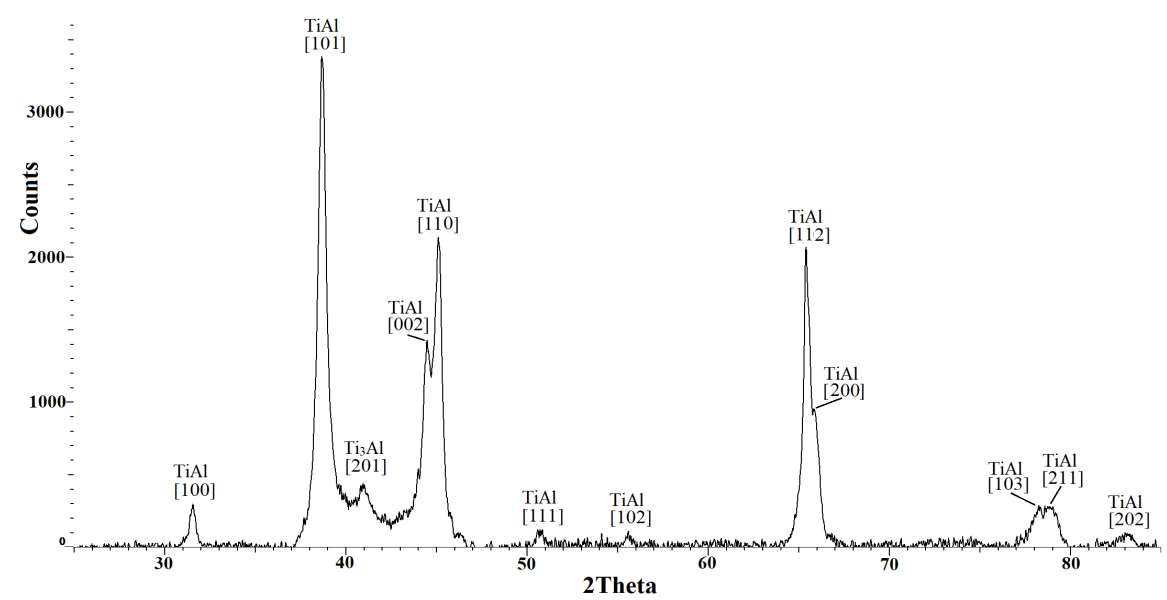

Figure 1. Full XRD pattern of commercial GE48-2-2 alloy.

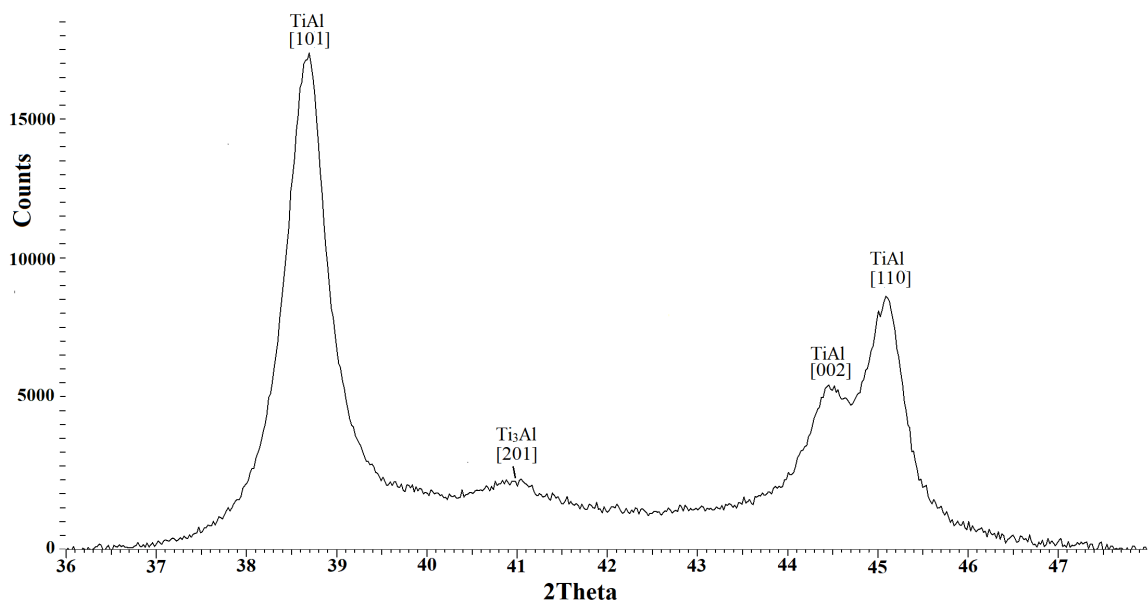

Figure 2. Remeasured part of the pattern of Figure 1 at $2 \theta 36$ - 48 degrees sub-range. 


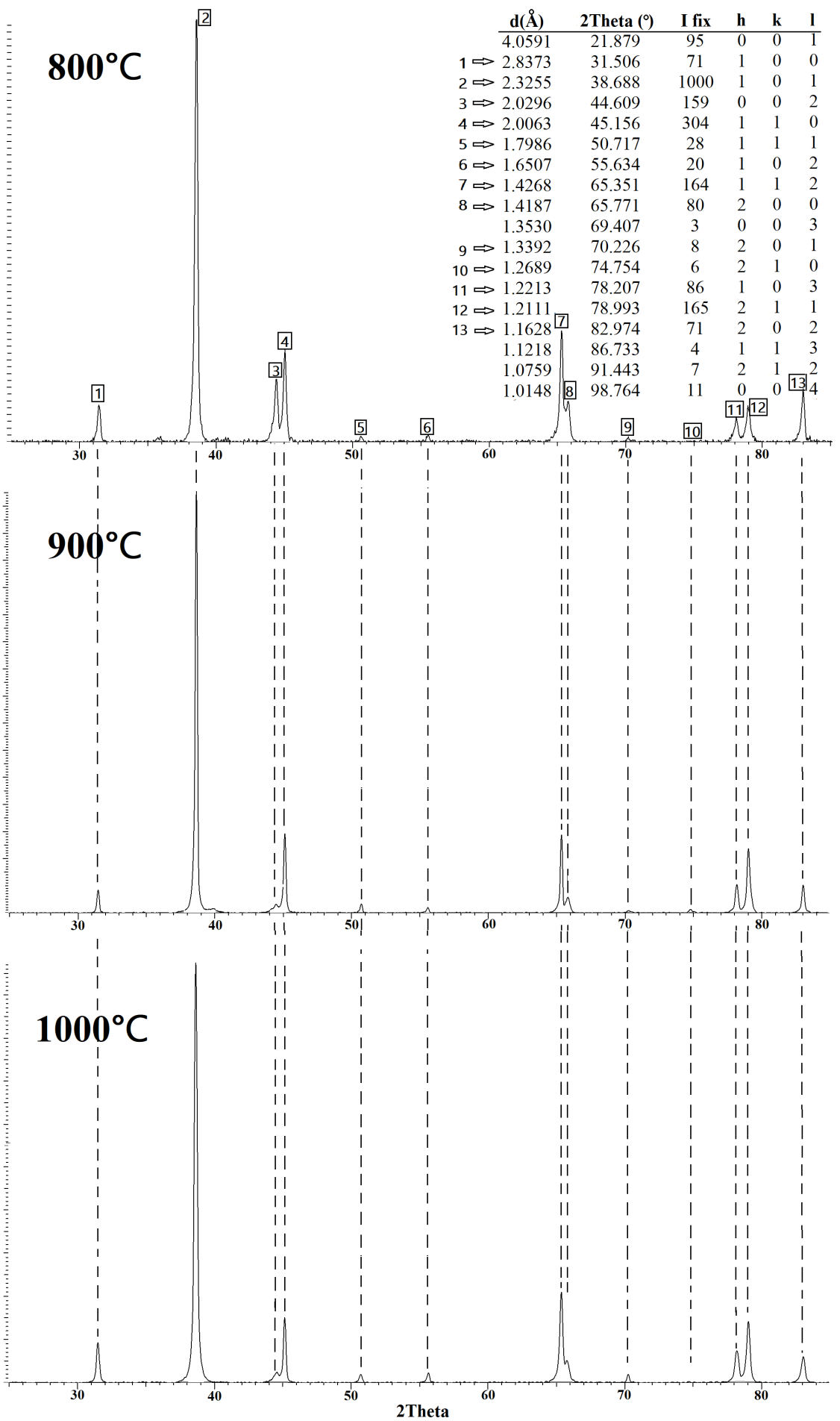

Figure 3. Full XRD pattern of the substrate after non-boriding treatment at $1073 \mathrm{~K}, 1173$ $\mathrm{K}$ and $1273 \mathrm{~K}$ for 10 hours. In the table (up-right) the crystallographic data of $\gamma$-TiAl phase's peaks are depicted.

In Figure 4 the XRD spectrum of borided layer is presented. In Figure 5 the pattern of limited $2 \theta$ range from 33 to 47 degrees for better analysis is presented. This layer was created with boronizing treatment at $1273 \mathrm{~K}$ for 10 hours. 


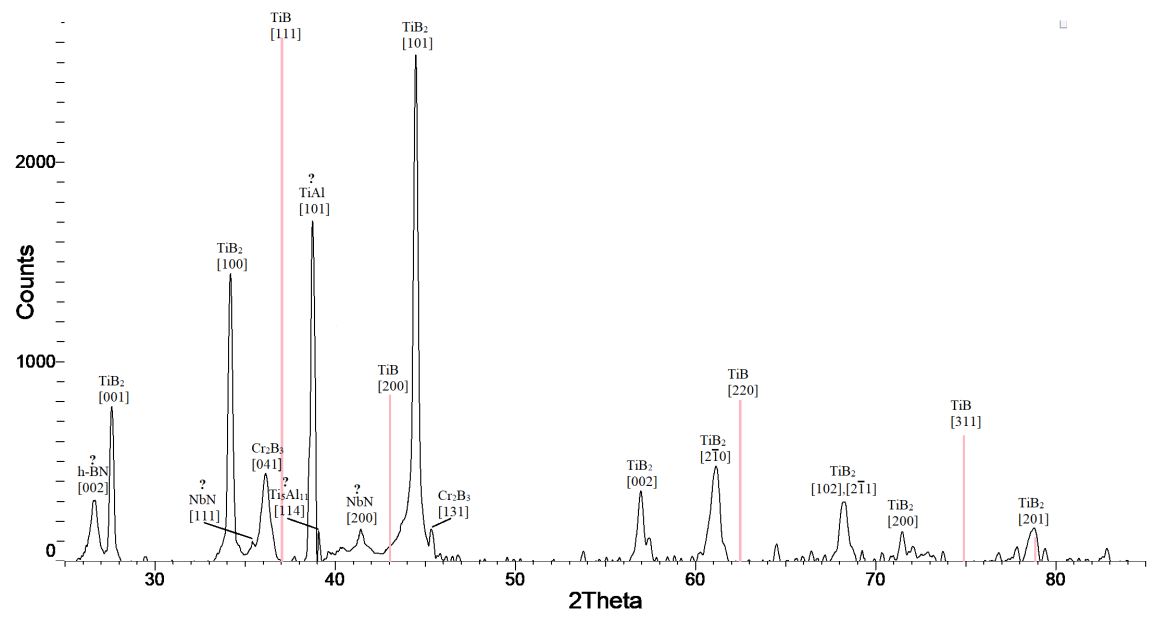

Figure 4. Full XRD pattern of borided layer after boronizing treatment at $1273 \mathrm{~K}$ for 10 hours (red lines correspond to $\mathrm{TiB}$ phase peaks, in order the total absence of $\mathrm{TiB}$ phase to be clear).

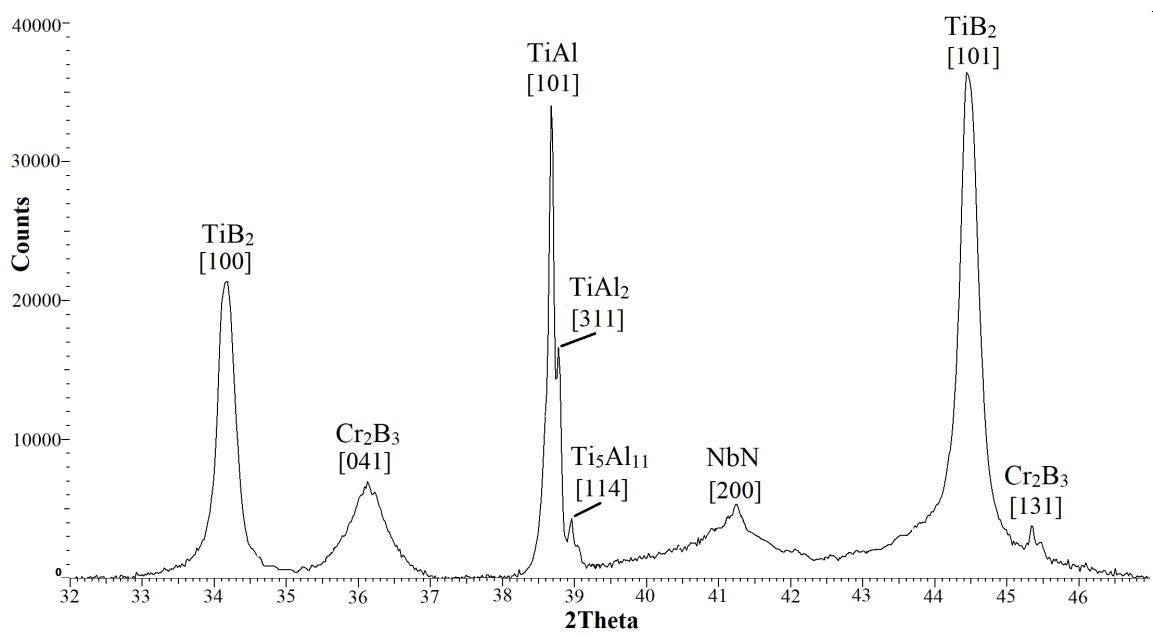

Figure 5. Remeasured part of the pattern of Figure 4 at $2 \theta 32$ - 47 degrees sub-range.

Moreover, a variety of secondary phases was revealed such as $\mathrm{TiAl}_{2}$ and $\mathrm{Ti}_{5} \mathrm{Al}_{11}$. During the boriding process, a diffusion mechanism seems to hold near the surface, leading to an alteration of the local equilibrium composition, which in turn results in formation of the mentioned above Al-rich phases, appeared to be formed between the $\mathrm{TiB}_{2}$ needles. It is more probably that the Al-rich phases were formed because of the fact that a part of the Ti atoms was consumed for the formation mainly of $\mathrm{TiB}_{2}$.

There is no evidence of $\mathrm{TiB}$ formation, in spite that elsewhere was referred to be observed [14] [15] [16]. Contrariwise, only $\mathrm{TiB}_{2}$ was formed as it is clearly observable in Figure 4 and Figure 5. This is a very important detail that contributes to the evaluation of the quality of the coating, because the mechanical properties of $\mathrm{TiB}$ phase are inferior in comparison to $\mathrm{TiB}_{2}$ [17]. The absence of $\mathrm{TiB}$ is probably due to the fact that the diffusion of boron was not facilitated through the coating layer. The Boron also seems to form a small amount of a 


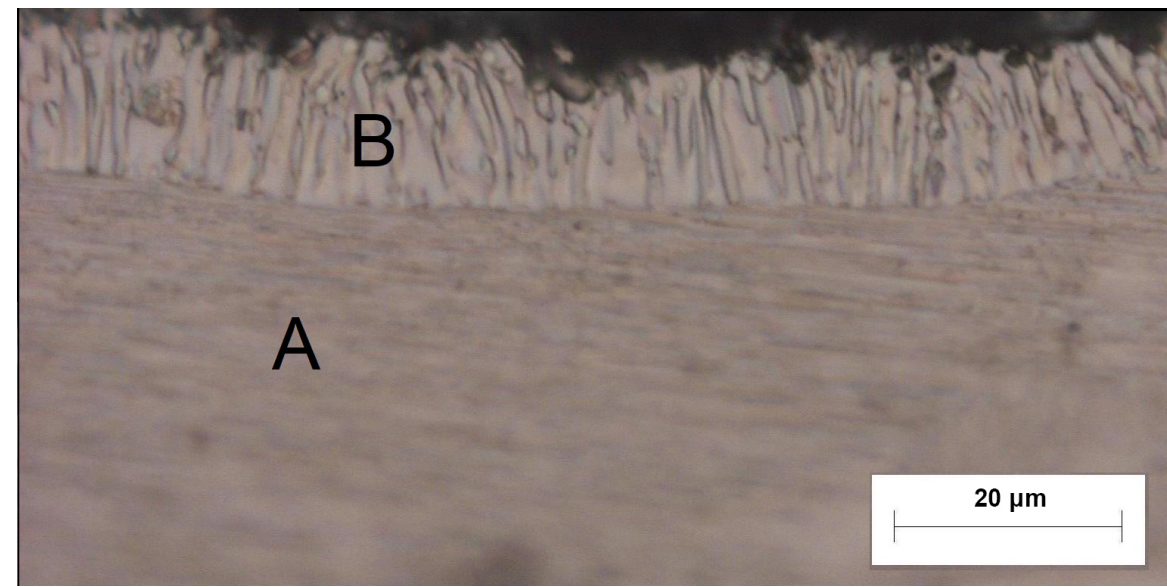

Figure 6. Metallographic image of the coating layer (A: $\gamma$-TiAl substrate, B: boride coating).

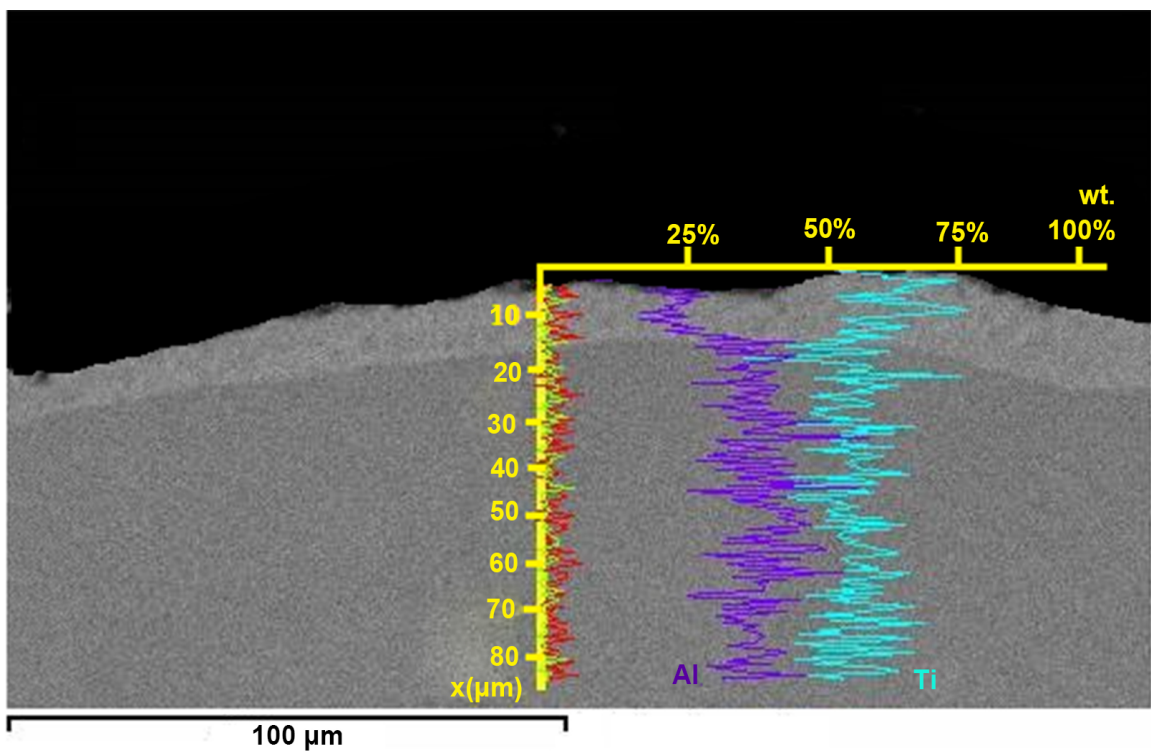

Figure 7. SEM image of coating layer after boronizing and chemical analysis profile for the elements $\mathrm{Ti}$ (light blue), $\mathrm{Al}$ (purple) $\mathrm{Nb}$ (red), $\mathrm{Cr}$ (green).

boride with Chromium, $\mathrm{Cr}_{2} \mathrm{~B}_{3}$ (Figure 5). The $\mathrm{Cr}_{2} \mathrm{~B}_{3}$ is a hard phase that enhances the quality of the coating [18]. Moreover, $\mathrm{NbN}$ (Figure 5) was probably formed, which contributes to the superficial strengthening of the material [19].

Finally, there is a strong evidence of the formation of a hexagonal (graphite-like) Boron Nitride, h-BN (Figure 4). Normally, the $\mathrm{BN}$ is formed in the case that an $\mathrm{NH}_{4} \mathrm{Cl}$ activator is used [10]. However, in our case is obvious that the presence of $\mathrm{BN}$ in the coating is caused by the atmospheric Nitrogen traces, as we did not use a Nitrogen containing activator. The substrate is not sufficiently approachable from the X-ray beam, so the $\gamma$-TiAl phase peaks on XRD pattern (Figure $4 \&$ Figure 5) are not enough intense [20] [21].

For additional aspect of the coating, a metallographic image is presented in Figure 6. 
In Figure 7 a SEM image of the coating layer is presented.

The image (Figure 7) revealed a 10 - $15 \mu \mathrm{m}$ thick $\mathrm{TiB}_{2}$ layer. Moreover, the linear chemical profile across the coating layer for the elements $\mathrm{Ti}$ (light blue), $\mathrm{Al}$ (purple), $\mathrm{Nb}$ (red), $\mathrm{Cr}$ (green) is presented. The coating layer, as shown clearly in Figure 6, seems to consist of two phases. The atomic ratio Al:Ti in the coating, as extracted from elemental analysis via SEM (Figure 7), is significantly diminished. The majority of $\mathrm{Ti}$ atoms have being consumed in the formation of the $\mathrm{TiB}_{2}$ phase. Thus, a large amount of $\mathrm{Al}$ atoms were deliberated from the initial $\gamma$-TiAl phase. Part of these $\mathrm{Al}$ atoms seemed to form the detected via XRD Al-rich phases $\mathrm{TiAl}_{2}$ and $\mathrm{Ti}_{5} \mathrm{Al}_{11}$. The rest of the $\mathrm{Al}$ atoms have been moved towards the surface, following a reverse diffusion path. After that, an oxidation reaction of $\mathrm{Al}$ atoms took place and the oxide that was formed peeled off due to its weak adhesion with the coating layer.

\section{Conclusions}

From the above described results we deduce the following:

- The boronizing treatment leads to the formation of a coating layer, that includes the desirable $\mathrm{TiB}_{2}$ phase with sufficient hardness (up to $\mathrm{HV}=1400$ ).

- The TiB phase is totally absent from the spectrum.

- The substrate undergoes a modification during the boronizing process, being transformed into a pure $\gamma$-TiAl material.

- The same modification is present during non-boriding annealing of the pure substrate at the same time and temperature conditions. Consequently, this modification is independent of the presence of Boron.

\section{Acknowledgements}

The authors acknowledge Mrs. Dabou Xanthi for carrying out the XRD measurements and Assoc. Prof. Pavlidou Eleni for conducting the SEM measurements. This research has been financially supported by General Secretariat for Research and Technology (GSRT) and the Hellenic Foundation for Research and Innovation (HFRI) (Scholarship Code: 530).

\section{Conflicts of Interest}

The authors declare no conflicts of interest regarding the publication of this paper.

\section{References}

[1] Appel, F. and Oehring, M. (2003) $\gamma$-Titanium Aluminide Alloys: Alloy Design and Properties. In: Leyens, C. and Peters, M., Eds., Titanium and Titanium Alloys, WILEY-VCH Verlag GmbH \& Co. KGaA, Weinheim, 89-152. https://doi.org/10.1002/3527602119.ch4

[2] Popela, T., Hamáček, J., Kützendörfer, J. and Vojtěch, D. (2011) The Influence of Tantalum on the High Temperature Characteristics of Lamellar Gamma + Alpha 2 Titanium Aluminide. Materials Science and Engineering, 528, 8557-8564. 
https://doi.org/10.1016/j.msea.2011.07.070

[3] Popela, T., Kubásek, J., Maixner, J., Novák, P. and Vojtěch, D. (2011) Comparison of $\mathrm{Nb}$ - and Ta-Effectiveness for Improvement of the Cyclic Oxidation Resistance of TiAl-Based Intermetallics. Intermetallics, 19, 493-501. https://doi.org/10.1016/j.intermet.2010.11.025

[4] Miura, K. and Yoshihara, M. (1995) Effects of Nb Addition on Oxidation. Intermetallics, 3, 357-363. https://doi.org/10.1016/0966-9795(95)94254-C

[5] Swadzba, L., Moskal, G., Jarczyk, G., Aguilar, J. and Goral, M. (2011) Diffusion Aluminide Coatings for TiAl Intermetallic Turbine Blades. Intermetallics, 19, 744-747. https://doi.org/10.1016/j.intermet.2010.12.015

[6] Thongtem, T., McNallan, M., Thongtem, S. and Sopunna, K. (2004) Surface Modification of the $\gamma$-TiAl Alloys by the Nitridation. Surface Science, 566-568, 810-815. https://doi.org/10.1016/j.susc.2004.06.113

[7] Ma, X.X., Zhao, X.G., Zhang, F., Shi, J.Y., Zhang, J. and Liang, W. (2007) Oxidation Kinetics of the Pack Siliconized TiAl-Based Alloy and Microstructure Evolution of the Coating. Intermetallics, 15, 1-8. https://doi.org/10.1016/j.intermet.2005.11.038

[8] Anthymidis, K.G., Stergioudis, G. and Tsipas, D.N. (2002) Boride Coatings on Non-Ferrous Materials in a Fluidized Bed. Science and Technology of Advanced Materials, 3, 303-311. https://doi.org/10.1016/S1468-6996(02)00038-4

[9] Anthymidis, K.G., Tsipas, D.N. and Stergioudis, G. (2001) Boriding of Titanium Alloys in a Fluidized Bed Reactor. Journal of Materials Science Letters, 20, 2067-2069. https://doi.org/10.1023/A:1013510629005

[10] Vázquez-Alcázar, M.R., Ruiz Navas, E.M., Gordo, E. and Tsipas, S.A. (2010) Boride Coatings Obtained by Pack Cementation Deposited on Powder Metallurgy and Wrought Ti and Ti-6Al-4V. Surface \& Coatings Technology, 205, 2340-2347. https://doi.org/10.1016/j.surfcoat.2010.09.026

[11] Vojtěch, D. and Popela, T. (2012) Characterization of Pack-Borided Last-Generation TiAl Intermetallics. Surface \& Coatings Technology, 209, 90-96. https://doi.org/10.1016/j.surfcoat.2012.08.034

[12] GfE (2010) Data Sheet for $\gamma$-TiAl 48-2-2 Ingots. https://www.gfe.com/fileadmin/user_upload/pdfs/Produktspezifikationen_Titaniu m_Aluminides/PDB_gamma-TiAl_48-2-2-Ingot_V2.pdf

[13] Lei, M.K., Zhu, X.P., Han, S.Q., Wang, D.Y., Wang, F.G. and Wang, F. (2000) Effect of Borate Coating on Oxidation Resistance of $\gamma$-TiAl Intermetallic Compound. $\mathrm{Ma}$ terials Chemistry and Physics, 65, 249-252. https://doi.org/10.1016/S0254-0584(99)00263-1

[14] Aich, S. and Ravi Chandran, K.S. (2002) TiB Whisker Coating on Titanium Surfaces by Solid-State Diffusion: Synthesis, Microstructure, and Mechanical Properties. Metallurgical and Materials Transactions A, 33, 3489-3498. https://doi.org/10.1007/s11661-002-0336-6

[15] Atar, E., Kayali, E.S. and Cimenoglu, H. (2008) Characteristics and Wear Performance of Borided Ti6Al4V Alloy. Surface \& Coatings Technology, 202, 4583-4590. https://doi.org/10.1016/j.surfcoat.2008.03.011

[16] Li, F., Yi, X., Zhang, J., Fan, Z., Gong, D. and Xi, Z. (2010) Growth Kinetics of Titanium Boride Layers on the Surface of $\mathrm{Ti}_{6} \mathrm{Al}_{4 \mathrm{~V}}$. Acta Metallurgica Sinica (English Letters), 23, 293-300. https://doi.org/10.1016/S1006-7191(07)60042-8

[17] Madtha, S., Lee, C. and Ravi Chandran, K.S. (2008) Physical and Mechanical Properties of Nanostructured Titanium Boride (TiB) Ceramic. Journal of the American 
Ceramic Society, 91, 1319-1321. https://doi.org/10.1111/j.1551-2916.2007.02246.x

[18] Okada, S., Atoda, T. and Higashi, I. (1987) Structural Investigation of $\mathrm{Cr}_{2} \mathrm{~B}_{3}, \mathrm{Cr}_{3} \mathrm{~B}_{4}$, and $\mathrm{CrB}$ by Single-Crystal Diffractometry. Journal of Solid State Chemistry, 68, 61-67. https://doi.org/10.1016/0022-4596(87)90285-4

[19] Borcz, C., Lepienski, C.M. and Brunatto, S.F. (2013) Surface Modification of Pure Niobium by Plasma Nitriding. Surface \& Coatings Technology, 224, 114-119. https://doi.org/10.1016/j.surfcoat.2013.03.008

[20] Azaroff, L.V. (1968) Elements of X-Ray Crystallography. McGraw-Hill Inc., New York.

[21] Koch, B., MacGillavry, C.H., Milledge, H.J., Koopmans, K., Rieck, G.D. and Bacon, G.E. (1968) Measurements and Interpretation of Intensities: Absorption. In: MacGillavry, C.H. and Rieck, G.D., Eds., International Tables for X-Ray Crystallography, The Kynoch Press, Birmingham, Vol. III, Ch. 3.2, 157-169. 